\begin{tabular}{|c|c|c|c|c|c|}
\hline MUNIBE Antropologia-Arkeologia & $n^{\circ} 70$ & $271-283$ & DONOSTIA & 2019 & ISSN 1132-2217 • eISSN 2172-4555 \\
\hline
\end{tabular}

\title{
Nueva lectura e interpretación del ara de Cabriana (Lantarón, Álava) dedicada a las Ninfas: HAEp 2531
}

\author{
New reading and interpretation of the altar from Cabriana \\ (Lantarón, Alava) dedicated to the Nymphs: HAEp 2531
}

PALABRAS CLAVES: (Dii) Boni; Locus sacer; sacrum; teónimos; epítetos.

GAKO-HITZAK: (Dii) Boni; Locus sacer; sacrum; teonimoak; epitetoak.

KEY WORDS: (Dii) Boni; Locus sacer; sacrum; divine names; epithets.

Pilar CIPRÉS ${ }^{(1)}$ y Ma Cruz GONZÁLEZ-RODRíGUEZ ${ }^{(2)}$

\section{RESUMEN}

El objetivo de este trabajo es el estudio del ara de Cabriana (Lantarón, Álava) - HAEp 2531- dedicada a las Ninfas. El análisis detallado de la pieza permite proponer una nueva lectura e interpretación de la misma en el marco de la religión romana provincial, que modifica las valoraciones históricas anteriores.

\section{LABURPENA}

Lan honen helburua Ninfei eskainitako (Lantaron, Araba) Cabrianako araren - HAEp 2531-ikerketa da. Piezaren azterketa zehatzak irakurketa berri bat egitea ahalbidetzen du, probintziako erlijio erromatarren markoaren barruan interpretatuz. Interpretazio honek aurreko balorazio historikoak aldatzen ditu.

\section{ABSTRACT}

This paper studies the altar HAEp 2531 discovered out of archaeological context near the Roman villa of Cabriana (Lantarón, Álava, Spain) in 1919. It is currently preserved in the BIBAT-Archaeology Museum in Vitoria-Gasteiz (Álava) with the inventory number 106.

In $1925 \mathrm{~J}$. Miguel de Barandiarán published it for the first time with the following transcription: Nymph / bonis et / locos, and the translation "To the good Nymphs and places". This is the reading that has been accepted by scholars until now.

The detailed analysis and review of the altar leads to suggest a new interpretation for the lines 1 and 3: Nymf(is) et / Bo.ni.s / et. Lo.Co.s(acrum siue-acro), that could be translated as "Consecrated to the Nymphs and to the Good (Gods) and to the Place" or "To the Nymphs and to the Good (Gods) and to the Sacred Place".

The absence of archaeological context or any other significant chronological indications make it difficult to date the inscription accurately. Therefore, it is only possible to estimate a broad chronology between the 2nd and 3rd centuries.

The new interpretation of the text together with the examination of similar inscriptions of the Western Roman Empire change the historical conclusions of previous studies and situate the dedication in a Roman religious context. Thus, the altar has to be understood within the framework of the principles of the well-known ancient polytheism. The inscription is dedicated to the Nymphs, the (Dii) Boni and the sacred space. The association of the Nymphs with other divinities is not surprising, since it is attested in many inscriptions. Additionally, the interpretation of the text as a dedication to a locus sacer would link these divinities with a natural space. Unfortunately, the absence of the mention of the cultor or cultores makes it impossible to determine the private or public nature of the altar.

\section{PRESENTACIÓN Y CONTEXTUALIZACIÓN DEL EPÍGRAFE}

La pieza objeto de estudio es un ara de arenisca hallada en Cabriana (Lantarón, Álava) en el año 1919, fuera de contexto arqueológico. Según Barandiarán (1925: 47) "al abrir los cimientos de una presa junto al río Ebro, en término de Cabriana cerca de Miranda de Ebro, fue hallada un árula (piedra arenisca de forma rectangular, de 0,64 m. de altura) dedicada a las Ninfas y Lugares, según nos lo da a conocer la inscripción que tiene en una de sus caras". Esta información es tomada por Corta (1928: 331) y los autores posteriores. En la cara posterior del ara ha sido grabado en mayúsculas el siguiente texto: "Apareció en / Cabriana / río Ebro / MCMXIX".

En la actualidad se conserva depositada en el BlBAT-Museo de Arqueología con el $n^{\circ}$ de inventario 106.

\footnotetext{
(1) Departamento de Estudios Clásicos. Facultad de Letras. UPV/EHU. C/ Francisco Tomás y Valiente, n 1, E-01006 Vitoria-Gasteiz. e-mail: pilar.cipres@ehu.eus.

(2) Departamento de Estudios Clásicos. Facultad de Letras. UPV/EHU. e-mail: cruz.gonzalez@ehu.eus
} 
En la Antigüedad el yacimiento de Cabriana, identificado como una uilla desde el siglo XVIII (Instituto Alavés de Arqueología 1981; Torres 1981) se localizaba en el territorio de la polis de Deobriga mencionada por Ptolomeo en II, 6, 52, y en las proximidades de la uia XXXIV ab Asturica Burdigalam donde esta ciuitas es recogida como una mansio.

En esta misma localidad se han encontrado también, hasta el momento y en diferentes contextos, otros cinco epígrafes de los cuales tres son de carácter religioso -CIL II, 2924, actualmente desaparecido, $A E$ 1986, 402, ambas de lectura insegura, y Abásolo y Elorza 1974: 251-; uno funerario -CIL II, 2925-y un posible miliario -CIL II, 4902- (Lostal 1992: 173-174, n 169).
El ara realizada en arenisca, con base y coronamiento moldurados, aparece rematada por un focus y dos puluini, entre los que se aprecian restos de un pequeño frontón. El zócalo, que no presenta restos de molduración en su cara posterior, solo conserva la mitad izquierda ligeramente desgastada, donde también se ha perdido la esquina trasera. El dado presenta un buen estado de conservación salvo un desconchado en el ángulo superior derecho que afecta parcialmente a las últimas letras de la primera línea del campo epigráfico. El coronamiento aparece muy erosionado en su cara frontal, excepto en el ángulo izquierdo, mientras que en el lado posterior ha desaparecido la esquina superior izquierda, lo que afecta a todas las molduras y a parte del puluinus.

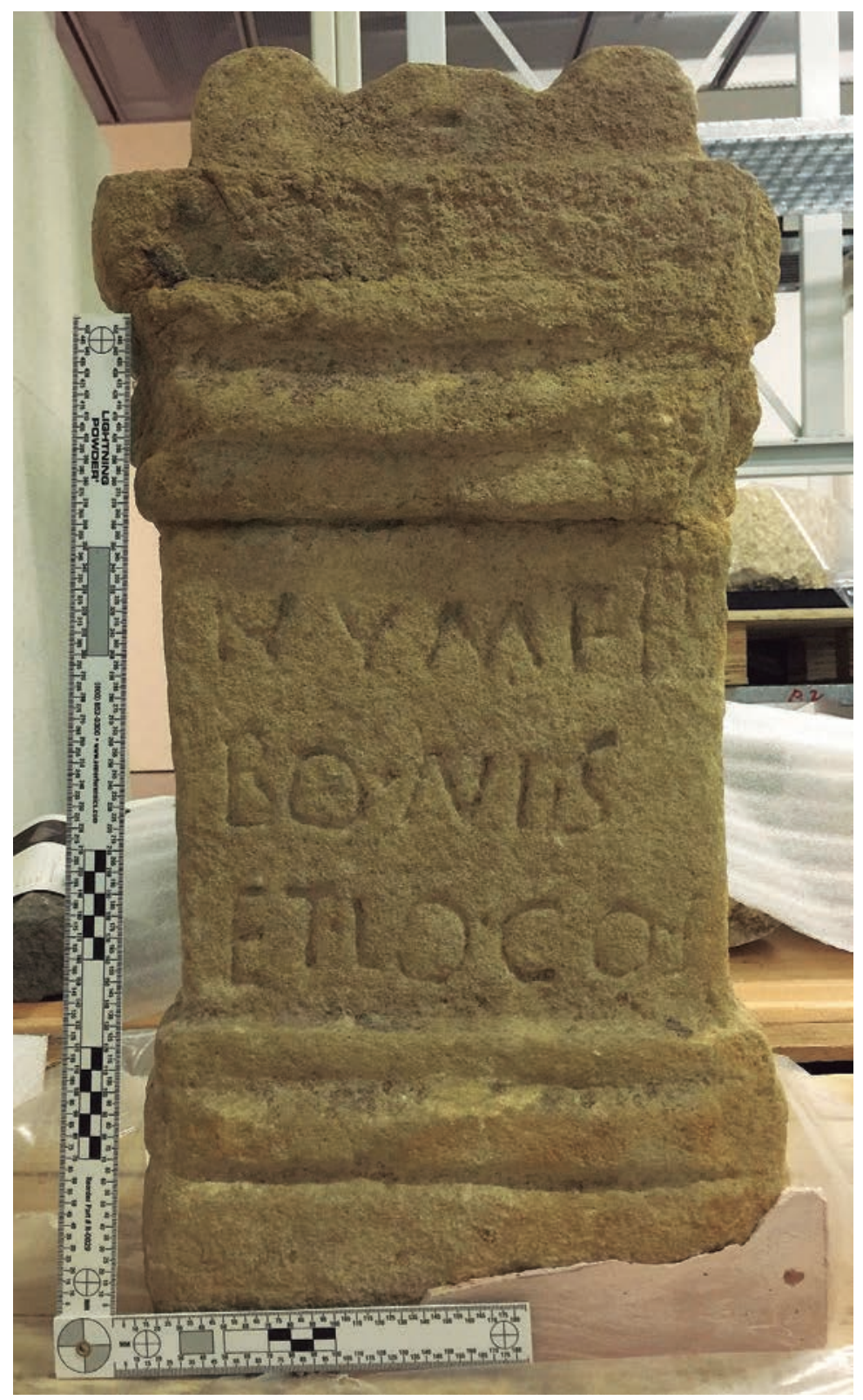

Fig. 1. Ara de Cabriana (Lantarón, Álava): HAEp 2531. / Altar from Cabriana (Lantarón, Álava): HAEp 2531. 
Las dimensiones de la pieza son $60 \times 31,5$ (corresponde a la moldura superior del ara, donde se conserva íntegra) × 20 cm; el zócalo mide ca. 15,3 × 29,5 × 18,4/5,3 $\mathrm{cm}$ y presenta tres molduras irregulares en su forma y ejecución. De ellas la mejor conservada es la superior, que solamente presenta pequeños golpes en la esquina y el lateral derechos. Su altura es de $2,5 \mathrm{~cm}$ y su perfil es ligeramente curvo en la cara frontal y las laterales. La segunda, desgastada en ambas esquinas y de perfil suavemente curvo como la anterior, sobresale del resto y presenta una altura de $4 \mathrm{~cm}$. Por último, la inferior con una altura de $8 \mathrm{~cm}$ es recta y está separada de la anterior por una profunda línea incisa. El cuerpo central mide $23 \mathrm{~cm}$ de alto mientras que la anchura oscila entre los 26 de la parte superior y los 25,5 de la inferior con un fondo de $16 \mathrm{~cm}$. El coronamiento, con unas medidas máximas de $21,5 \times 31,5 \times 20 \mathrm{~cm}$, presenta cuatro molduras irregulares. La superior, de perfil recto, sobresale del resto y mide 5,2 cm de altura. La segunda, de menor tamaño $-2,5 \mathrm{~cm}-$, también presenta el perfil recto. La tercera, suavemente curvada hacia abajo, tiene una altura de 4,5 $\mathrm{cm}$, mientras que la inferior, también recta, mide $3 \mathrm{~cm}$. El focus, bien conservado -a pesar del desconche que afecta a la parte trasera- es una circunferencia de $11 \mathrm{~cm}$ de diámetro, en la que es visible el punto central.
Los puluini, ambos de $6 \mathrm{~cm}$ de ancho, tenían una longitud máxima de $16 \mathrm{~cm}$, conservada en el derecho, mientras que el de la izquierda ha perdido casi el tercio posterior ( $11 \mathrm{~cm}$ conservados en el lado externo). Su cara frontal está desgastada, sobre todo en el lado derecho, sin que se observen restos de decoración. Entre los dos puluini se sitúa un pequeño frontón roto en la parte superior, que mide $4,5 \mathrm{~cm}$ de alto por 7 de largo.

El campo epigráfico, que ocupa toda la cara frontal del fuste, no se encuentra delimitado. Su estado de conservación es bueno, permitiendo la lectura del texto a excepción del final de la primera línea donde el desconchado antes comentado afecta a parte de las dos últimas letras. El texto está distribuido en tres líneas y aparece casi centrado, con un intento de ordinatio a la izquierda con una distancia de $2 \mathrm{~cm}$ de la arista lateral. Por el contrario, en el lado derecho el sangrado es desigual, de modo que en la I. 1 es inexistente y en la I. 2 alcanza los 4,9 cm. La distancia respecto a la parte superior oscila entre los $3 \mathrm{~cm}$ y los $1,5 \mathrm{~cm}$ de las dos últimas letras, que son de mayor tamaño. Respecto a la parte inferior la l.3 presenta una separación máxima de 2,3 cm y una mínima de 1,6 cm. El tamaño irregular de las letras condiciona las medidas del interlineado, que entre las líneas I y 2 oscila entre 4,5 y 2,7 cm (entre la M

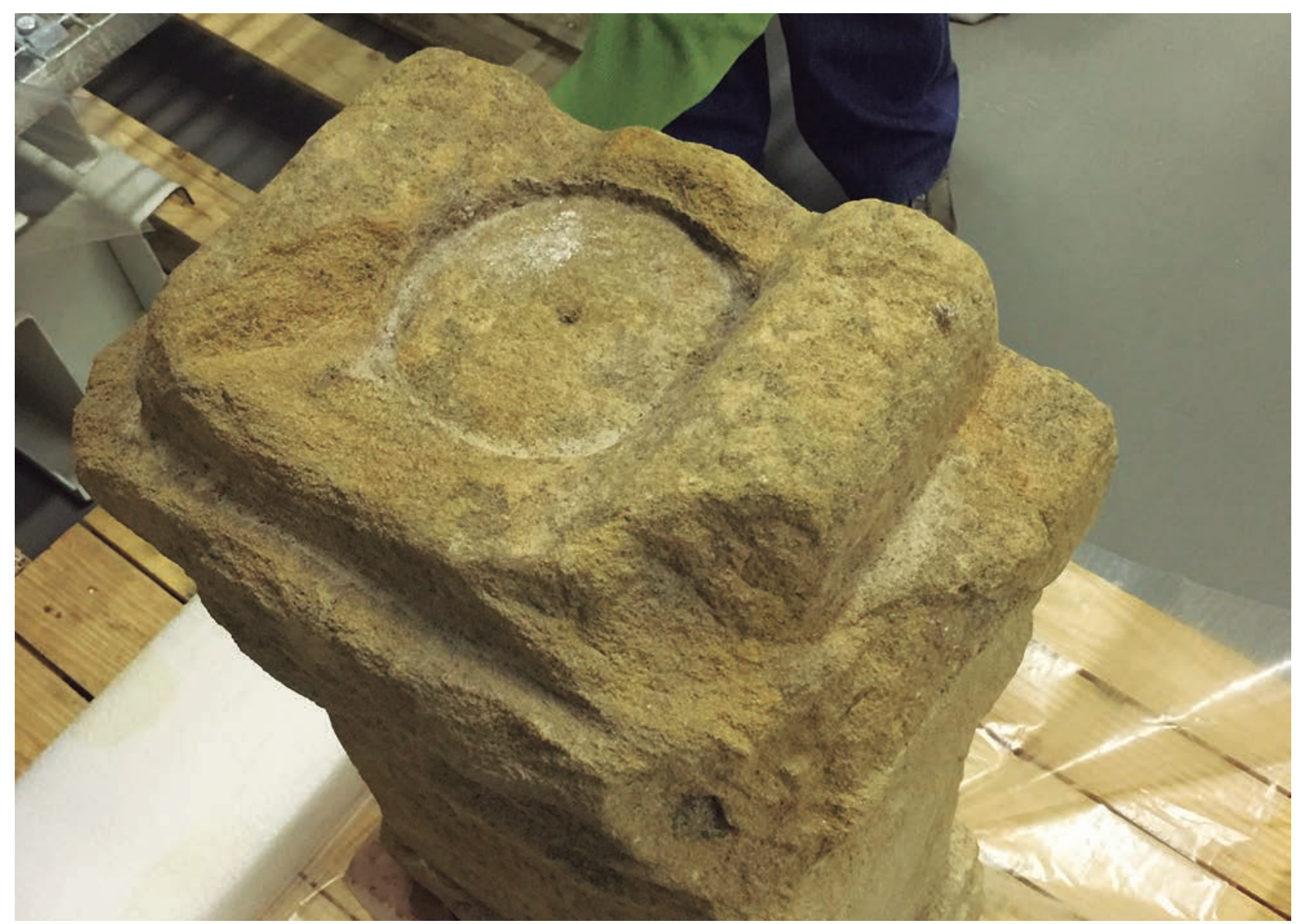

Fig. 2. Detalle del focus y los puluini. / Detail of the focus and the puluini. 
y la N: 3,6 cm; entre la M y la I: 4,5 cm; entre B y N: 3,5 cm y entre la línea de escritura y la $S: 2,7 \mathrm{~cm}$ ) y entre las 2 y 3 entre 3,7 y 3,2 cm (entre la B y la $\mathrm{E}: 3,2 \mathrm{~cm}$, entre la O y L: $3,7 \mathrm{~cm}$. y entre la $S$ y la $C: 3,4 \mathrm{~cm}$ ). Parece que el titulus intenta respetar la línea de escritura, al menos en los dos primeros renglones, mientras que en el tercero la $T$ y la $L$ han sido grabadas más altas. Las letras carecen de remates y son irregulares, tal y como se observa en la $\mathrm{N}$ de la I. 1 y 2, la $\mathrm{O}$ de la I. 2 y 3 y la $S$ de I. 2 y 3. En la I. 1 la $\mathrm{N}$ presenta el primer trazo vertical, mientras que en la I. 2 son todos oblicuos y de tamaño desigual. La S es más curvilínea en la I. 2 que en la 3, donde es más abierta y algo menos profunda. La M es abierta, siendo de menor tamaño la segunda mitad $(3,1 \mathrm{~cm})$, y la B de panzas desiguales y ligeramente angulosas. La L presenta el trazo horizontal corto. La E muestra los trazos horizontales del mismo tamaño y el central aparece a mitad del asta vertical. La T muestra el travesaño centrado y recto. El tamaño de las letras conservadas totalmente varía dentro de cada línea:

Línea 1: N: 3,1; Y: 3,2; M: 3,5; F: 4,4

Línea 2: B: 4,5; O: 3,7; N: 3,6; I: 3,5 y la S: 5,5

Línea 3: E: 4,6; T: 3,8; L: 3,1; O: 4; C: 3,6; O: 3,2 y S: 4,3

La distancia entre las letras es bastante regular. Por su parte, el grabado es desigual cambiando de unas letras a otras, sin ser idéntico ni tan siquiera en

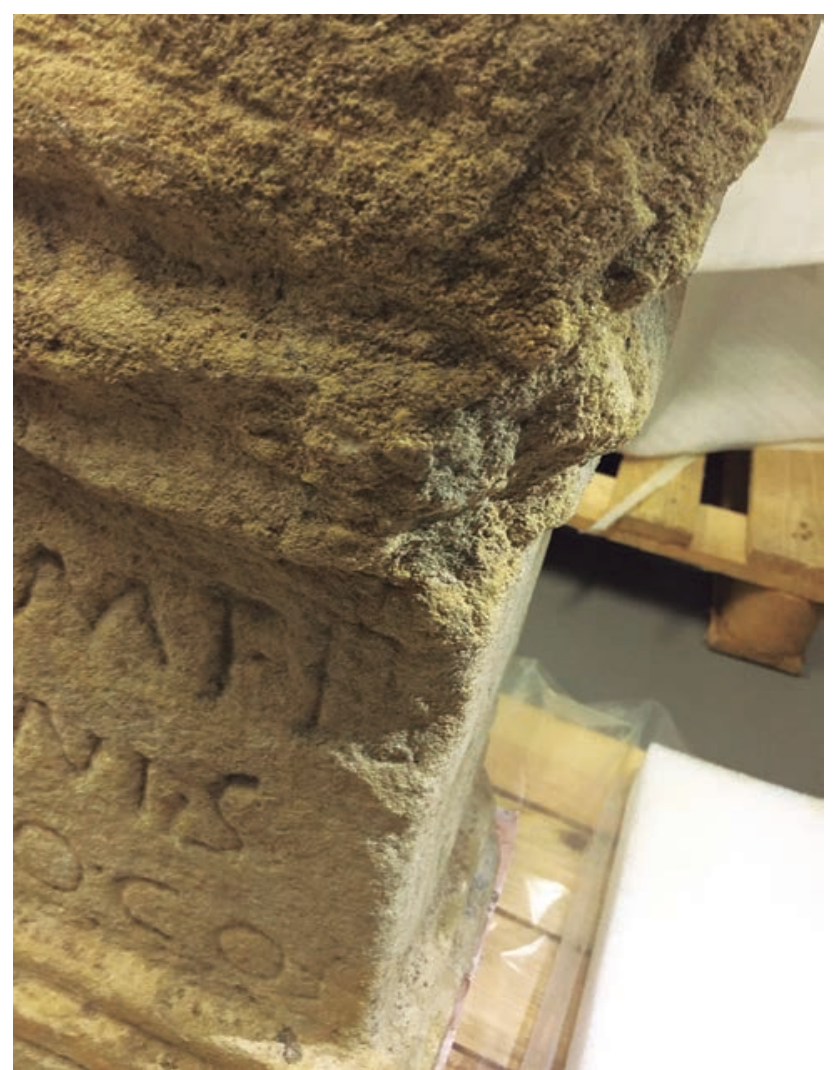

Fig. 3. Desconche al final de la línea 1 / Damage at the end of the line 1 una misma línea. En las líneas 1 y 2 es profundo y biselado excepto en las dos últimas letras de la primera, que además se han visto desgastadas por la erosión. En la línea 3 las letras ET y L muestran un grabado profundo pero menos biselado, mientras que las dos últimas letras están más apagadas por la erosión, especialmente la $S$.

En las líneas 2 y 3 se utilizan signos de interpunción que son triangulares en la primera y circulares en la segunda, donde la segunda interpunción se prolonga hacia abajo por una incisión grabada en su momento o causada por un golpe posterior. En ambos casos han sido grabados a distinta altura y dispuestos cada dos letras, salvo en la S final.

\section{LECTURA}

La editio princeps fue realizada por Barandiarán (1925: 47). Su lectura ha sido seguida por Corta (1928: 331); HAEp, 253; Elorza (1967: 135, n 20); Solana (1978: 174, n62) y Ortiz de Urbina (1985: 199, n¹8):

\section{NYMPH}

BONIS

\section{ET LOCOS}

traduciendo "A las Ninfas buenas y Lugares" 
Las variantes que se han venido dando a esta lectura corresponden a la primera línea. Albertos (1970: 164) lee Nimph(is) sustituyendo la Y por I. Más recientemente Andreu (2012: 344 y 2017b: $n^{\circ} 4$.2) y Olivares-Pedreño (2013: 65) cambian la $\mathrm{M}$ por una $\mathrm{N}$, restituyendo $\mathrm{Ny}$ nph[is]. Sin embargo, la autopsia de la pieza nos lleva a modificar algunas de las letras propuestas hasta ahora.

El examen directo de la inscripción permite afirmar con seguridad la lectura de las tres primeras letras, NYM, debiendo descartarse, por un lado, la I de la propuesta por Albertos y la $\mathrm{N}$ que algunos autores identifican.

Más problemática resulta la lectura $\mathrm{PH}$. Tras la $\mathrm{M}$ lo que se observa con claridad es una $F$, con el travesaño inferior menos marcado y algo más corto $(2,1$ $\mathrm{cm})$ que el superior $(2,5 \mathrm{~cm})$. Mayor dificultad presenta la identificación del extremo final de la línea, debido al desconche y erosión sufridos por esa parte del campo epigráfico, como ya hemos mencionado.

En una primera aproximación podría leerse, tal y como aparece en la bibliografía, una $\mathrm{H}$, lo que ha dado lugar a identificar la letra anterior como una $\mathrm{P}$, asociando la grafía $\mathrm{PH}$, habitual en los testimonios epigráficos en los que se documenta este teónimo. El examen detallado permite afirmar que no se trata de la letra $P$, puesto que presenta dos trazos horizontales rectos que no cierran. No obstante, un estudio minucioso del texto permite reconocer la existencia de dos letras en lugar de la pretendida $\mathrm{H}$. En primer lugar, se puede identificar una $E$ de la que son visibles los trazos superior y central, faltando el trazo inferior debido al deterioro de la pieza. A continuación se perciben los restos de otra letra, que puede identificarse como una $\mathrm{T}$, cuyo trazo horizontal es perfectamente reconocible. De esta se conserva aproximadamente la mitad superior $(2,5 \mathrm{~cm})$, habiendo desaparecido el resto por el desconche señalado. Estas dos últimas letras son de mayor tamaño que las restantes. Así la $\mathrm{E}$, que conserva el asta vertical entera, mide 5 $\mathrm{cm}$, aproximándose a la $\mathrm{F}$ que la precede y a la $\mathrm{E}$ de la I.3. Del mismo modo, la T final, cuyo trazo horizontal de $2,5 \mathrm{~cm}$ se une con el de la $\mathrm{E}$, parece que tendría la misma altura. Según lo comentado, la lectura del texto, en nuestra opinión, quedaría como sigue:

\section{NYMF·Ẹ T}

$\mathrm{BO} \cdot \mathrm{NI} \cdot \mathrm{S}$

\section{$\mathrm{ET} \cdot \mathrm{LO} \cdot \mathrm{CO} \cdot \mathrm{S}$}

De lo anterior se deduce que la transcripción de la primera línea debe ser: Nymf(is) et. Si bien la grafía F no es la más frecuente, la hallamos documentada en
Hispania en CIRGI, 38 y, posiblemente en CIL II, 2530, así como en otros epígrafes del occidente del Imperio como, por ejemplo, en Lupa 25, 465 -Nimfis-, CIL VI, 36818 -Nymfabus-, CIL XIII, 6649 -Nymfae- o CIL XIV, 4321 -Numfabus- (Lhote-Birot 2004: 67).

Independientemente de la variante ortográfica que presente el teónimo, la transcripción del epígrafe aceptado por los autores que se han ocupado de su estudio ha sido Nymph(is) Bonis et Locos. Según la lectura que ofrecemos, se debe corregir la asociación de Bonis como epíteto de las Ninfas.

Por lo que respecta a la tercera línea, siempre se ha transcrito como et Locos, lo que implica una falta de concordancia gramatical entre el primer vocablo y el último. Elorza (1967: 135, n²0) en su trabajo sobre la epigrafía alavesa señala: "Es de advertir que las lápidas votivas van generalmente puestas en dativo, y caso menos frecuente en genitivo con el epíteto Sacrum. Sin embargo, la segunda divinidad a la que está dedicada esta árula, a los Lugares, no observa esta regla, caso extrañísimo, sino que va en acusativo, sin concordar con el sustantivo anterior". Esta discordancia fue explicada, desde el punto de vista lingüístico, por Albertos (1970: 164) como muestra de "un latín superficial aprendido por el grabador y tal vez por el propio dedicante, cuyo nombre desconocemos, aunque puede ser latino, porque el conjunto de la región está muy romanizado. Discordancias casuales son frecuentes en el latín vulgar, sobre todo entre gentes que sólo utilizarían el latín como lengua oficial"1. Sin embargo, la tercera línea puede ser valorada de otra forma atendiendo, por un lado, a la sintaxis y, por otro, al lenguaje religioso utilizado habitualmente en las inscripciones de esta naturaleza. De esta forma la S final puede entenderse sin dificultad como la abreviatura de $s(\text { acrum })^{2}$ o de $s$ (acro), adjetivo bien documentado en la epigrafía romana de carácter sagrado.

Esta valoración permite entender el término Loco como un dativo que concuerda con los precedentes a los que está unido por la conjunción et. Esta interpretación elimina el problema de la discordancia entre el dativo de los vocablos anteriores y el acusativo con el que se identificaba la forma Locos. Por todo lo dicho, la transcripción del texto quedaría como sigue:

Nymf(is) et / Bo.ni.s / et $\cdot$ Lo co.s(acrum siue -acro)

La ausencia de contexto arqueológico, de elementos cronológicos internos claros (Raepsaet-Charlier 1993, 2001; Cibu 2003 con amplia bibliografía) así como la imposibilidad de utilizar criterios paleográficos

\footnotetext{
1 Y prosigue. "Cf. p. ej. las inscripciones cántabras de Vadinienses y Orgenomescos en que discordancias de este tipo están bien documentadas (...), en que las oposiciones están en nominativo, y los antropónimos en dativo". Siguen esta misma valoración Solana (1978: 191) y más recientemente Olivares-Pedreño (2013: 65).

2 Vid. esta interpretación en Fernández Corral 2016: 237-238 nº 7.
} 


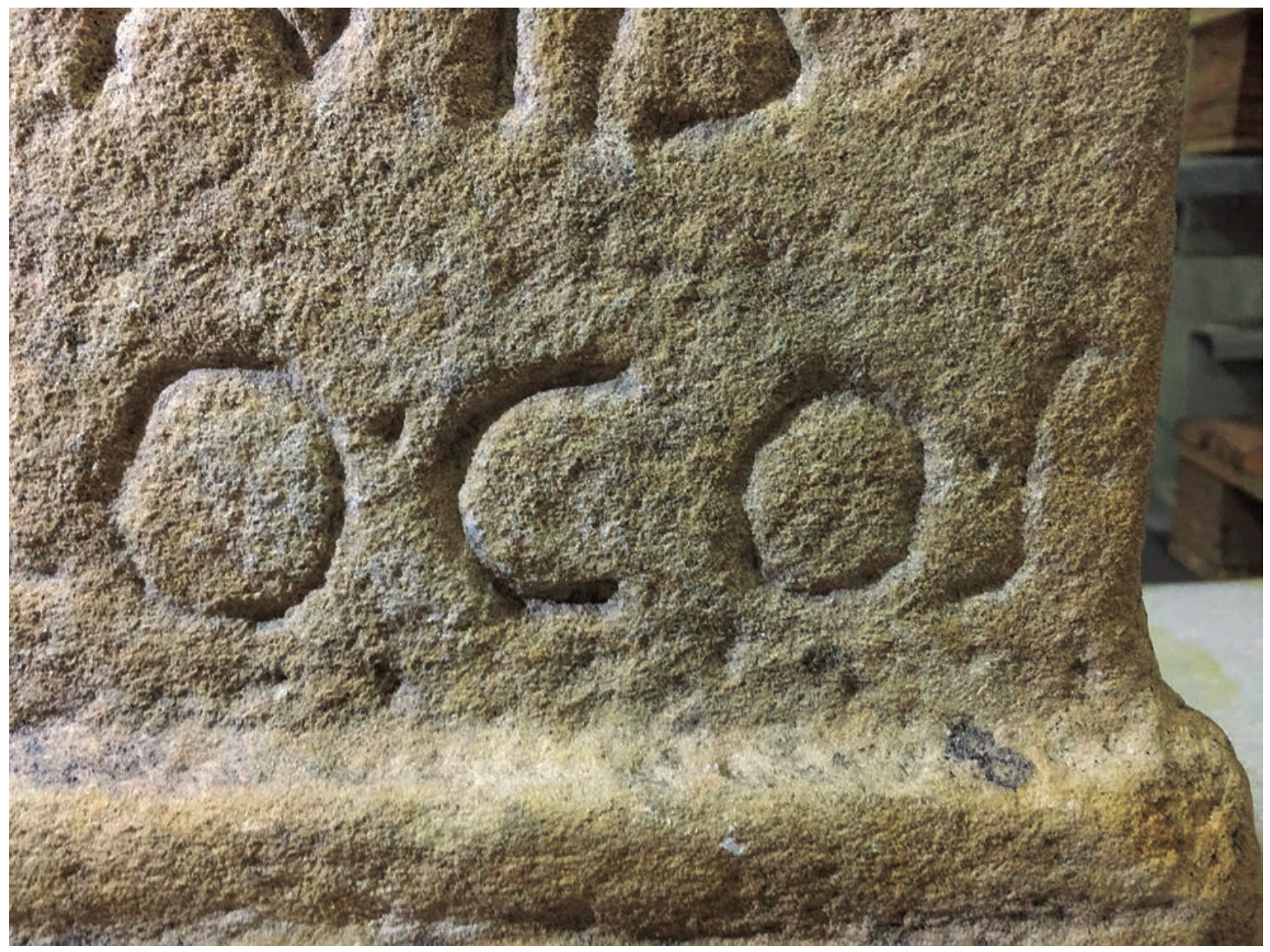

Fig. 4. Detalle de la línea 3. / Detail of the line 3

seguros hacen extremadamente difícil la datación de este monumento. En este sentido solo podemos proponer una fecha amplia que lo enmarca entre los siglos II y III.

\section{INTERPRETACIÓN DEL EPÍGRAFE Y COMEN- TARIO HISTÓRICO}

\subsection{Ninfas}

Esta inscripción ha sido puesta en relación con otros dos epígrafes dedicados a las Ninfas y hallados, respectivamente, en Araya (Álava) -en la actualidad desaparecida- y en la misma Cabriana. Según indica Baraibar y recoge Elorza (1967: 127, nº 8) el primero "se halló con otras tres en el Nacedero", de donde fluye el río Ciranuza, a 120 m sobre la fábrica metalúrgica de Araya. En su descripción señala que las letras estaban "casi desvanecidas por la acción del agua en que estuvo sumergida la piedra" ${ }^{3}$. La transcripción que hace del texto es como sigue:
CAPITO·AR

NYM//IS

//SVIT

IBENSMER

ITO

Lectura: Capito ar(am) Nym(ph)is (po)suit (I)ibens merito.

Dado su mal estado de conservación su lectura plantea serios problemas para la identificación segura del teónimo. Además, la desaparición del epígrafe impide una comprobación del texto, que debemos considerar, al menos, hipotético.

El segundo epígrafe, actualmente depositado en el Museo BIBAT -Museo de Arqueología, $n^{\circ}$ de inventario 75- publicado por Abásolo y Elorza (1974: 250-251, $n^{\circ 1}$, fig. 3) fue descubierto en la tercera campaña de excavaciones arqueológicas realizadas en la villa ro-

\footnotetext{
${ }^{3}$ Baraibar en su manuscrito indica que, "de las otras tres árulas encontradas, una quedó en la orilla de la fuente y otra más pequeña la guarda el Sr. Ajuria en su palacio". Ambas tienen restos de inscripciones completamente ilegibles.
} 
mana de Cabriana (Álava). Se trata de un ara de arenisca moldurada en el basamento y en el coronamiento y con un focus, con dimensiones máximas de 0,65 x 0,40 $\mathrm{cm}$. Lo que más Ilama la atención es la presencia de letras apenas marcadas, lo que da la sensación de que no se había terminado de grabar, sino que estaba en proceso de realización. La lectura que se ha dado es V(otum) [s(oluit) l(ibens)] m(erito) / Ninph(is).

Por otro lado, los estudios realizados sobre la epigrafía de la zona han venido vinculando estas Ninfas con divinidades "indígenas" de carácter acuático, poniéndolas en relación con los teónimos de carácter local aparecidos en la misma zona. De este modo Albertos (1970: 164 y 165), como había valorado mucho antes Leite de Vasconcellos ${ }^{4}$, piensa que las Ninfas pueden ser consideradas como deidades "indígenas" vinculadas con aguas salutíferas de distintos tipos ${ }^{5}$. Esta investigadora, a su vez, las relaciona con el teónimo Varna documentado en un ara recogida por Prestamero (Real Academia de la Historia 1802) -actualmente desaparecida- procedente también de Cabriana e interpretado como una divinidad acuática (Albertos 1970: 165). Prestamero ya indicaba que su estado de conservación no era bueno y transcribe el texto que él reconoce, añadiendo el siguiente comentario: "El V VARNAE está en la parte superior del ara bien conservada, pero tan maltratadas las demás letras a pedradas por los muchachos, que apenas se pueden leer". Hübner (CIL II, 2924) copia la lectura de Prestamero e identifica Vuarnae con la divinidad y los investigadores posteriores han mantenido esta lectura como segura, considerando el teonimo VVarna siue Varna como una divinidad indígena femenina y ofreciendo diferentes explicaciones etimológicas del mismo, bien por el vascuence o por las lenguas indoeuropeas ${ }^{6}$.

Sobre su naturaleza Baraibar, en un texto manuscrito, señala que "Vvarna designaría a alguna diosa acuática, moradora de alguna fuente vecina o del Ebro, muy próximo a Cabriana". Coincidiendo con este autor, Albertos (1970: 162) incide en su carácter acuático, señalando que "por el contexto" el ara estaría dedicada "a una deidad salutífera, probablemente algún manantial, o tal vez el mismo Ebro". El problema una vez más es, como ha señalado Olivares-Pedreño (2002: 130), que este teónimo se registra en un texto que plantea serias dudas de lectura.

Por su parte Beltrán-Lloris y Paz (2004: 343) añaden a la relación de las Ninfas con Varna la de estas con Leucina/Liucma, teónimo también inseguro documentado en un ara de Comunión (Álava). No obstante, la autopsia de este epígrafe conservado en la iglesia parroquial de Comunión (Álava) no permite sostener esta lectura dado el deterioro del texto.

En nuestra opinión, teniendo en cuenta los problemas insalvables de lectura de los dos teónimos anteriores, conviene, desde un punto de vista metodológico, ser muy prudentes a la hora de establecer esta asociación entre la divinidad clásica de las Ninfas y unas hipotéticas divinidades locales de nombres inseguros, dado que cualquier conclusión al respecto resulta imposible de demostrar. Hasta el momento no contamos con ninguna inscripción que permita vincular los tres teónimos.

Volviendo al ara de Cabriana, las divinidades que se mencionan en primer lugar son las Ninfas, tradicionalmente asociadas en el mundo romano a las aguas, tal y como se puede ver en Toutain (1905: 381): "Le rôle essentiel des êtres divins, qui portaient dans la langue latine le nom de Nymphae, était de présider aux sources ordinaires, à celles dont l'eau ne possédait aucune vertu spéciale, comme aux sources termales ou médicinales. Tel est bien le caractère que presente le culte des Nymphae dans la plupart des provinces latines"; en Navarre (1907: 127-128) y en Wisowa (1912: 219-225). Esta misma vinculación se encuentra en los trabajos realizados sobre el culto a las Ninfas en el conjunto de Hispania o para un ámbito más reducido (Diez de Velasco 1998: 82-99 y 2008: 462-465; Ruiz-Sáez, 2008; Andreu 2012; 2017a y b). Sin embargo, también debe tenerse en cuenta la posibilidad de que estas divinidades en el mundo romano, al igual que en el griego, aparezcan vinculadas no solo a las aguas sino también a los árboles y las montañas, tal y como muestran las distintas fuentes ${ }^{7}$. Frente a la división clásica que ofrece, por ejemplo, Navarre (1907) entre la realidad griega y la romana (con su vinculación específica con las aguas), más recientemente Scheid (2012)

\footnotetext{
${ }^{4}$ Este investigador ya había dicho que el nombre latino Nimphae traduce "algumas vezes creenças pre-romanas, sobretodo, nas inscripçoes do Norte" (Leite 1905: vol. 3, 258-259).

5 Albertos 1970: 164: "Señalamos, no obstante, que el culto a las Ninfas encubre frecuentemente cultos indígenas a divinidades fluviales, que a veces pueden reconocerse por sus epítetos, cuando están expresos. Cf. p. ej. Varcilensis, Transtaganis, Lupianis, etc. Pero en el caso de las inscripciones de Araya ignoramos cuál puede ser el nombre con que estas divinidades acuáticas eran conocidas en la región". Andreu (2012: 335, n. 23), por su parte, indica que "(...) el lugar de hallazgo de algunas de las piezas procedentes del conventus Cluniensis parecen subrayar de nuevo el carácter tópico más que el salutífero de la advocación a las Nymphae en esta zona".

${ }^{6}$ Baraibar interpreta el teónimo Vuarna por el vascuence al considerarlo compuesto a base de Ur, agua, y barna, interior. Según indica Albertos (1970: 162 y 163), Varna estaría plenamente en el cuadro de la hidronimia europea primitiva y señala que "sin embargo, aunque estemos de acuerdo en que $\vee$ Varna sea una deidad acuática, no creemos que se pueda explicar por el vascuence por ser la región muy indoeuropeizada y romanizada, y por la misma estructura de la palabra".

7 Serv., In Vergilii Aeneidos Libros, 1, 500: Oreades Nymphae montium Oreades dicuntur, siluarum Dryades, quae cum siluis nascuntur Amadryades, fontium Napeae uel Naides, maris uero Nereides. Sobre las restantes fuentes en las que se observa la relación de las Ninfas con los árboles y las montañas vid. Scheid, 2012.
} 
sostiene, tras el análisis de las fuentes clásicas, que estas divinidades se asocian en todo el mundo antiguo a ambos elementos. Dado el lugar de aparición de la inscripción que nos ocupa, se puede pensar que las Ninfas en ella mencionadas están relacionadas con las aguas, no obstante no podemos obviar su posible vinculación con los árboles o los montes (Andreu 2012), puesto que como ha demostrado Scheid no se puede establecer una vinculación exclusiva y automática con las aguas, como documenta, por ejemplo, CIL III, 6478 de Panonia: Nymphis / quae in nemore / sunt arulam / T(itus) Pomponius Atticus / numini / adiut(rici) deuotum / d(e)d(icauit).

\subsection{Bonis}

Como hemos señalado anteriormente, el vocablo bonis siempre se ha interpretado como un epíteto de las Ninfas, dado su uso frecuente como determinante divino (De Ruggiero 1961: vol I, 1017-1018; Ehmig 2015: 13), sin profundizar en su significado. Hasta el momento se trataría del único testimonio en el que se asocian ambos (Ruiz-Sáez 2008: 223-224), siendo los epítetos frecuentes de las Ninfas, tanto en Hispania como en el resto del Imperio, aquellos referidos a las características intrínsecas de las aguas en general (perennes, aeternae, nouae) o de las aguas termales (medicae, salutiferae, salutares) ${ }^{8}$. Por su parte el término bonus, a, um se documenta en la epigrafía ${ }^{9}$ como componente fijo del nombre de algunas divinidades, como es el caso de Bona Dea, Bona Fortuna y Bonus Puer. En otras ocasiones se utiliza como epíteto de las divinidades abstractas Bonus Euentus, Bonum Fatum, Bona Mens, Bona Spes, Bona Conscientia, Bona Victoria, etc. (Ehmig 2015: 10-13; véase también la reflexión de Scheid 2005).
Aunque no es demasiado frecuente, también aparece en la epigrafía sagrada ya sea referido a una sola divinidad -Letinno bono de la Galia Narbonense (CIL XII, 2990) y Venus bona del carmen de Tívoli (CIL XIV, 3565) - o a varias. En algunos casos se constata acompañado del vocablo latino deus/-a, como en Siluanus deus bonus (AE 2008, 503) en singular o Dii Boni en plural. En este segundo caso encontramos ejemplos en los que esta forma está asociada a dos o más teónimos. Así, en Numidia se registra Dii Boni seguido inmediatamente de Mars Gradiuus Pater et Victoria Sancta ( $A E$ 1919, 27); de Numini Praesenti Aesculapius et Salus (AE 1973, 630) y de Aesculapius et Hygia ${ }^{10}$. Estas últimas divinidades aparecen también en Dacia precedidas de Dii Magni et Boni (CIL III, 1560) ${ }^{11}$. La estructura de estos textos permite plantear la hipótesis de que la expresión Dii Boni pueda estar haciendo referencia a los dioses mencionados de forma explícita en el epígrafe. La misma suposición cabe plantear para la inscripción recientemente aparecida en Olisipo (FE 128, 2015, $541)$, en la que la expresión Dis Bonis, en este caso abreviada, parece hacer referencia a las dos divinidades que a continuación se mencionan: $D$ (is) $B$ (onis) Sac(rum) Cinteri et Muno...12

Más problemática resulta la valoración de dos epígrafes de Numidia consagrados a los Dii Boni (D. B. S., es decir, D(iis) B(onis) S(acrum), CIL VIII, 8246 y 8247 ) en los que se recoge una ofrenda sacrifical de nueve uictimae hecha por el cultor-sacerdos Saturni- a diferentes divinidades: Dominus, Tellus, Iuppiter, Nutrix, Hercules, Mercurius, Venus y Testimonius ${ }^{13}$. A diferencia de los casos anteriores, en estos textos la invocación a los Dii Boni no va seguida inmediatamente del nombre de las divinidades, sino de la mención del cultor, lo que nos lleva a considerar la posibilidad de que en ellos el formulario $D$. B. S. se pueda interpre-

\footnotetext{
8 Además de estos epítetos, las Ninfas aparecen asociadas a otros determinantes de naturaleza variada. Vid., Navarre 1907:127-128; Wissowa 1912: 223 n. 8; Diez de Velasco 1998: 82-100; Ruiz Sáez 2008: 224.

${ }^{9}$ En las fuentes literarias la expresión Dii Bonii corresponde al formulario conversacional y se usa en vocativo, tal y como puede verse en autores como Plauto, Terencio, Cicerón, etc. Así, por ejemplo, en:

Cic., Brut., 288: "Demosthenem igitur imitemur.' o di boni, quid, quaeso, nos aliud agimus aut quid aliud optamus? at non adsequimur".

Cic., Tusc., 5, 19: "Nam quid profitetur? o di boni!"

Ter., And., 338: "Dauo: Di boni, boni quid porto? Sed ubi i nueniam Pamphilum, ut metum in quo nunc est adimam atque expleam animum gaudio?" Plaut., Ep., 539:

"-Per. Noscito ego hanc, nam uideor nescio ubi mi uidisse prius. Estne ea an non east quam animus retur meus?

-Phil. Di boni, uisitaui ** antidhac?

-Per. Certo east * " quam in Epidauro pauperculam memini comprimere".

En Plauto el término bonus también sirve de calificativo a las divinidades que oyen las súplicas: (Venus) Ptolemocratia: Qui súnt qui a patróna precés mea expetéssunt? nam uóx me precántum huc forás excitáuit. bonam átque obsequéntem deam átque haud grauátam patrónam exsequontur benignamque múltum (Rudens,260) y ...nunc Venerem hanc veneremur bonam, ut nos lepide adiuerit hodie (Ibidem, 305).

${ }^{10}$ Lambaesis (Numidia): Aescu/lapio et / Hygiae / dis Bonis / sacrum / Pelusii (CIL VIII, 2590); Di\{i\}s Bonis / Marti Gra/diuo patri et Victori/ae Sanctae /M(arcus) Aurelius / Decimus / u(ir) p(erfectissimus) p(raeses) p(rouinciae) N(umidiae) u(otum) I(ibens) s(oluit) (AE 1919, 27); Dis Bonis Numi/nibus Praesenti/bus Aesculapio / et Saluti sacrum / Aurel(ius) Decimus / u(ir) p(erfectissimus) p(raeses) p(rouinciae) Numidiae / ex principe pe/regrinorum / uotum soluit (AE 1973, 630).

${ }^{11}$ Mehadia (Dacia): Di\{i\}s Magnis / et Bonis Aescu/lapio et Hygiae / Marc(us) Aur(elius) Vete/ranus praef(ectus) leg(ionis) / XIII G(eminae) Gall(i)eniana(e) / u(otum) I(ibens) m(erito) p(osuit) (CIL III, 1560).

12 Vid. Hainzmann 2017: 261-263.

${ }^{13}$ Sebaï 2010: 273, n. 31, refiriéndose a estos dos textos, señala "ces deux inscriptions sont consacrèes aux Dii Boni, et offrent une liste de neuf animaux sacrifiés à des divinités spécifiques".
} 
tar como una advocación genérica. Sebaï (2010: 273) entiende que estos Dii Boni serían los propietarios del santuario sin identificarlos con el resto de las divinidades mencionadas en estas dos tarifas sacrificiales, del mismo modo que Deus Magnus en la inscripción votiva ILAlg. 2-3, 7574 ${ }^{14}$. La forma de consagración D. B. S. se repite en la inscripción ILAlg. 2-3, 8463 con la misma estructura que las dos anteriores.

En el caso del ara de Cabriana se registra únicamente la segunda parte del teónimo, debiendo sobreentenderse Dii. Aunque no contamos con otro testimonio idéntico a este, es conocida en las fuentes epigráficas la utilización de los epítetos como sustitutos del nombre de la divinidad. Ejemplos de este tipo están bien documentados en distintas provincias del Occidente referidos ya sea a divinidades locales o clásicas ${ }^{15}$. Tal vez, uno de los ejemplos más claros sea la utilización del calificativo Salutares. Como en el caso que nos ocupa, en las inscripciones se documenta como un adjetivo que acompaña a una divinidad -por ejemplo, a las Ninfas (entre otras, CIL III, 8167, 10891 y 10893; AE 1991, 908; $A E$ 1974, 397 y $A E 2014,1049)$ y a los Lares (CIL VI, 459)- o a varias, como Aesculapius et Hygia ( $A E$ 1915, 30). Igualmente en ILJug 3, 2881 aparece, como los Dii Boni, asociados al vocablo Dii: Dis / Salutari/bus Cn(aeus) Corne/lius Seuerus / ob periculum / quod euase/rat. Por último, también se atestigua solo la forma Salutares para designar a la divinidad, como se observa de forma clara en dos inscripciones de Dacia: Aesculapio / et Hygiae ce/terisq(ue) di\{i\}s dea/busq(ue) huisq(ue) / loci Salutarib(us)... (CIL III, 987) y Apol[I]ini Dianae / et Leto ceterisque / dis deab[us]q(ue) huis$q(u e)$ / loci Salutar[ib]us... ( $A E$ 1980, 735). Una situación similar la encontramos en el uso de Domina para aludir a la diosa Ataecina en un epígrafe de Lusitania -Dom(inae) / C(aius) Val(erius) T/elespho/rus ex ui/su et mo/nu[m(entum)] po/suit (Abascal 1995: 43-44; 64-67 fig. 41)- o Dominus para denominar a Saturnus en dos inscripciones de Numidia (CIL VIII, 8246 y 8247).
En la clasificación que Varrón ofrece en De Re Rustica (1.1.4 y 5) no figuran los Dii Boni a diferencia de los Dii Consentes y los Dii Magni o Dii Maiores. Por eso parece probable pensar que el calificativo Bonis corresponde a la valoración que hacen los cultores (Saglio 1877: 726) como divinidades propicias o favorables, como indica Macrobio refiriéndose a la Bona Dea: "Bonam quod omnium nobis ad uictum bonorum causa est (...)" (Sat. I, 12, 22). Todas las divinidades pueden ser Boni si actúan como se espera de ellas, incluidos los Dei Inferi'16.

Sobre el carácter de nuestro epígrafe no podemos afirmar con seguridad si se trata de una simple ofrenda, que busca la intervención favorable de la divinidad ante una petición anterior todavía no satisfecha (Sebaï 2010: 279), o si el monumento corresponde a un contexto votivo. Por el formulario atestiguado en algunas inscripciones, podemos deducir la presencia de los Dii Boni en la fase de la solutio, como en $A E$ 1919, 27, donde se lee u.l.s., y en $A E 1973,630$, con la fórmula desarrollada uotum soluit, ambas de Numidia. En el ara de Cabriana, por el contrario, la ausencia de este formulario nos impide poder afirmar que estemos ante un epígrafe votivo, puesto que no se menciona de forma explícita el cumplimiento del uotum (Scheid 1992: 34). Así mismo la omisión del cultor o cultores y su carácter complica aún más la comprensión global de este texto.

\subsection{Locus sacer siue locus sacrum}

Según hemos interpretado al comienzo de este trabajo, la letra S de la última línea del texto podría corresponder a la forma abreviada de sacrum, habitual en inscripciones de estas características. Si esto es así, la traducción del texto sería: "Consagrado a las Ninfas, a los (dioses) buenos y al lugar". Ya Barandiarán (1925) había indicado que la segunda divinidad a la que estaba dedicada esta árula era a los Lugares.

\footnotetext{
${ }^{14}$ Aziz Ben Tellis (Numidia): D(is) B(onis) s(acrum) / C(aius) Aponius / Secundus sa/cerdos agnu(m) Do/mino tauru(m) Domi/no ouicula(m) Nutri/ ci $<u=B>\operatorname{erbece}(m)$ loui ouicu/la(m) Telluri agnu(m) Herc/uli agna $(m)$ Veneri edu(m) / Mercurio uerbe (cem) Testi/monio [3]M[3]LXV (CIL VIII, 8246); D(is) B(onis) s(acrum) C(aius) C() Primus / sac(erdos) Saturni ag/nu(m) tauru(m) Dom/ino ouic(u)la(m) Tel[I]/uri <u=B>erbece(m) / [lou] o ouic $(u) l a(m) /[N u]$ trici capone $(m) /[H]$ erculi edu $(m)$ Merc/[urio] aedua $(m)$ Veneri <u=B>er/[bec]e $(m)$ Testimonio / [p]ecora / VIII[I] (CIL VIII, 8247); D(eo) M(agno?) s(acrum) / C(aius) Gargilius Zabo / intrauit sacerdos Saturni annis LXV u(otum) I(ibens) a(nimo) s(oluit) pecora VIIII agnu(m) tauru $(m)$ uerbece $(m)$ / ouicula $(m)$ gallinas V (ILAlg. 2-3, 7574).

${ }^{15}$ Vid. para las Galias: Lambert 2013: 114: "(...) la coexistence des Apollo Grannos et Apollo Belenos, par ex., doit nous conduire à admettre que les dieux galois avaient, dans certaines cas, plusieurs noms équivalents, entre lesquels il ne nous est pas possible de discerner une différence de statut, bien que cela soit possible en théorie. Cependant certaines épithètes gauloises associées aux théonymes latins se rencontrent aussi dans un emploi isolé, comme Atesmerios, Belatucadros, Belenos, Belisama, Boruu, Camulos, Cissonios, Cocidios, Latobios, Maponos, Marmogios, Nodons, Poeninos, Rudianos, Segomo, Taranucnos, Vindonnos, Vintios, Visucios... Cet emploi indépendent caractérise à mes yeux une "épiclèse" divine: c' est-à-dire soit un théonyme à part entière, soit une épithète reçue comme l'équivalent du théonyme -on pourrait dire, un surnom (dans le sens de "substitute de nom")". Para el caso de la Península Ibérica pueden verse, por ejemplo, Untermann 1985 y De Hoz 1986 y 1993.

${ }^{16}$ Bonus aparece también en una defixio procedente de Córdoba (CIL II2/7, 250) calificando a los Dei Inferi: Dionisia Denatiai / ancilla rogat deibus ego / rogo bono bono / deibus rogo oro bono /einferis bono Salpina / rogo oro et bonis inferis / ut dioso quod fit deibus / inferabus ut hoc quo(d) sit / causa et ecquod uotum / feci ut solua(t) rogo / ut illam ducas rogo /oro. Sobre su uso en defixiones vid. Ehmig 2015: 13. La cualidad propiciatoria se manifiesta de forma expresa en la fórmula Bonus Euentus semper propitius documentado en un grafito de Vindobona junto con otras divinidades portadoras del mismo atributo (Wedenig 2016: 94-96).
} 
Sin embargo, no se puede descartar la posibilidad de que la $S$ final estuviera aludiendo al carácter sagrado del lugar de culto, tal y como se documenta de forma clara ${ }^{17}$ en otros epígrafes de naturaleza religiosa, cuyo texto está desarrollado:

- CIL VI, 31071 (Roma, Italia): Locus / sacer.

- CIL X, 3756 (Sant'Arpino, Italia): Locus / sacer.

- LMentana 1, 16 (Prouincia incerta): Ara louis / locus / sacer.

El uso del término locus en una inscripción de Roma dedicada a Vesta y a las diosas Ninfas (CIL VI, 36818), antes mencionada, en la que esta expresión se asocia a sacerdos -sacerdos loci- refuerza esta idea. De la misma forma se documenta el término locus para aludir a un espacio sagrado en dos textos epigráficos de Ostia: CIL XIV, 58 y 59. El vocablo sacer (Castillo 2000: 84) alude a lo que pertenece a los dioses, tal y como indica de forma clara Macrobio: Sacrum est, ut Trebatius libro primo de religionibus refert, "quicquid est quod deorum habetur" (Sat., 3, 3, 2). Como señalan Dubourdieu y Scheid (2000, 60 ), el adjetivo sacer es una cualidad jurídica que los hombres otorgan a los lugares, objetos o personas. Tal y como acertadamente indican: "le termé sacré n'est pas, à proprement parler, une qualité divine que l'on constate dans un être ou une chose, mais c'est une qualité que les hommes y mettent. Ainsi, les dieux ne sont pas sacrés, et aucun objet ne peut être consideré comme divin. À Rome, le sacré n'est pas une "force magique" que l'on placé dans un objet, mais simplement une qualité juridique que cet objet possède du fait d'une décision humaine". Para que algo sea considerado sacer es necesario llevar a cabo un procedimiento perfectamente regulado en el derecho romano por medio del rito de la dedicatio-consecratio ${ }^{18}$. A través de él algo que hasta ese momento era profano, se convierte en sagrado al ser transferido a la propiedad divina, tal y como documenta Aulio Gelio, según transmite Festo (De verborum significatus, p. 424 y 424 L): Gallus Aelius ait sacrum esse, quocumque modo atque instituto ciuitatis consecratum sit, siue ara, siue signum, siue locus, siue pecunia, siue quid aliud, quod dis dedicatum atque consecratum sit (Delgado-Delgado 2016).
Lo más habitual es que el término locus se atestigüe en genitivo asociado a un teónimo que le precede, como por ejemplo Genius loci ( $A E$ 2001, 1540; AE 1946, 71; CIL IV, 1176), Nymphae loci (AE 1983, 711), Nymphae et Genius loci (AE 1962, 261) o Fortuna huius loci (CIL III, 10399), Genius et Fortuna Tutelaeque huius loci (CIL VI, 1176), Dis cultoribus huius loci (CIL VII, 980). A partir de estos testimonios Albertos (1970: 165) señaló para el epígrafe de Cabriana que "en cuanto a los Loci pueden ser espíritus de los lugares, como el Genius Loci de la religión romana (...)". Sin embargo, en el ara de Cabriana locus aparece en dativo. Si bien este uso no es muy frecuente, el testimonio de Cabriana no constituye un unicum, puesto que también se atestigua en el mismo caso en un epígrafe hallado en Ostia con el siguiente texto: Deaes Tribiaes santae et loco diuino l(ibens) $m$ (erito) u(otum) s(oluit) (N.S. 1953, p. 247, nr. 12; De Ruggiero 1961, vol IV, p. 1696). En ambos epígrafes va precedido de la conjunción et, lo que nos indica que los términos que une son de la misma entidad. En el epígrafe de Ostia tenemos a las diosas Tribias y al lugar divino. En Cabriana el monumento está dedicado no solo a las Ninfas y a los (dioses) buenos, sino también a un espacio sagra$\mathrm{do}^{19}$. Por tanto, parece claro que no estamos ante un error del lapicida, que haya sustituido un genitivo por un dativo, lo que nos llevaría a pensar en la fórmula "et (deo) loci sacrum", en alusión al dios del lugar. Así pues, la traducción del epígrafe quedaría como sigue: "A las Ninfas y a los (dioses) buenos y al lugar sagrado o inviolable".

Como desconocemos el contexto en el que se ubicaba el ara, no podemos precisar las características y la naturaleza de este lugar sagrado. Si tenemos en cuenta los epígrafes mencionados y las disposiciones recogidas en las leges ararum provinciales -Leges arae Augusti Narbonensi y Lex arae louis Salonitana ${ }^{20}$, no resulta inverosímil considerar que este locus sacer se pueda identificar con el area donde se erigió el ara o con la propia ara, tal y como se documenta en un epígrafe dedicado a I. O. M. y hallado en Germania Inferior (AE 1905, 235: ... "hu/nc locum siue / aram"...). Tampoco se deben descartar otras interpretaciones. Dada la naturaleza de las Ninfas, que en este caso aparecen

\footnotetext{
${ }^{17}$ No tomamos en consideración la inscripción CIL V, 2288 (Venecia, Italia), en la que presumiblemente se leería Hic locus / sacer est, debido a las dudas que suscita su autenticidad. Del mismo modo resultan incertae los epígrafes de Roma (CIL VI, 822 y 823$)$ recogidos por De Ruggiero (1961, vol IV p. 1698)

${ }^{18} \mathrm{Si}$ bien esta es la definición de la jurisprudencia romana cabe señalar que en la práctica epigráfica se puede encontrar la expresión sacer en textos funerarios, como en el caso de CIL X, 2015 donde se documenta la expresión "ab hoc loco sacro et religioso" (Laubry 2012: 7).

${ }^{19}$ Con este mismo significado vid., por ejemplo, CIL III, 11779 (Hainzmann 2006: 466-467, CF-Nor 068).

${ }^{20}$ Leges arae Augusti Narbonensis (FIRA 106; CIL XII, 4333): Cara Lateral: "(...) hanc aram dabo dedicabo/que, quas hic hodie palam dixero, uti infimum / solum huiusque arae titulorum / que est. Si quis tergere, ornare, / reficere uolet quod beneficii / causa fiat, ius fasque esto; siue / quis hostia sacrum faxit, qui / magmentum nec protollat, id / circo tamen probe factum esto; si / quis huic arae donum dare augereque uolet, liceto, eademq(ue) / lex ei dono esto, quae arae est; ceterae leges huic arae titulisq(ue) / eadem sunto, quae sunt arae / Dianae in Auentino. Hisce legi/ bus hisque regionibus sicuti / dixi, hanc tibi aram (...)".

Lex arae louis Salotinae (FIRA 107; CIL III, 1933): "(...) legem dixit in ea uerba quae infra scripta sunt: luppiter optime maxime, quandoque tibi hodie hanc aram / dabo dedicaboque ollis legib(us) ollisque regionibus dabo dedi/caboque, quas hic hodie palam dixero, uti infinum solum huius arae est (...)".
} 
mencionadas en primer lugar, se puede plantear también la hipótesis de que ese locus sacer aluda a un espacio natural (Scheid 2008: 626-627) -aquae, fuentes, árboles, montañas...- morada de estas divinidades ${ }^{21}$.

En cualquier caso, el desarrollo de la $S$ final bien sea como sacer o como sacrum nos sitúa ante una realidad religiosa romana, en la que locus estaría aludiendo a un espacio sagrado con todo lo que ello implica en el derecho religioso romano, ya se trate de la propia Roma o de las provincias, como bien ejemplifican las leges ararum mencionadas anteriormente.

\section{A MODO DE CONCLUSIÓN}

Según el análisis realizado, y si nuestra lectura e interpretación son correctas, estaríamos ante un texto que no presenta anomalías gramaticales, como hasta ahora se había venido manteniendo. El contexto al que nos remite es claramente un horizonte religioso romano y su contenido debe entenderse y explicarse en el marco de los principios bien conocidos del politeísmo antiguo. El epígrafe estaría dedicado a las Ninfas, a los (Dii) Boni y al espacio sagrado. No debe extrañar, por un lado, la asociación de las Ninfas con otras divinidades, puesto que la encontramos atestiguada epigráficamente en numerosos casos, y, por otro, con la dedicación al locus sacer dada la vinculación de estas divinidades con espacios naturales. Lamentablemente, la ausencia de la mención del o los cultores nos impide ir más allá en nuestras conclusiones y poder determinar el carácter privado o público del ara.

\section{AGRADECIMIENTOS}

Esta contribución se ha realizado en el marco de los proyectos HAR2015-65526-P (MINECO-FEDER, UE y PGC2018-097703-B-100 (MCIU/AEI/FEDER, UE) y en el de los grupos de Investigación GIU16/64 de la UPV/ EHU y IT698-13 del Sistema Universitario Vasco.

Agradecemos a Javier Fernández Bordegarai, Jefe del Servicio de Museos y Arqueología de Álava, a Jaione Agirre García, Técnica Responsable del BIBAT-Museo de Arqueología, y a Elisa García Retes, Técnica de esta Institución, las facilidades dadas y la ayuda prestada en todo momento para el estudio directo de la pieza, que tuvo lugar el 17 de mayo de 2017 y el 25 de junio de 2018. Igualmente damos las gracias a Pruden Gartzia, Director de la Biblioteca Azkue de Euskaltzaindia, por las gestiones realizadas para acceder a sus fondos bibliográficos.
También queremos expresar nuestro agradecimiento al Dr. José Delgado Delgado por su amabilidad al leer el texto y sus oportunas sugerencias. Sin embargo, cualquier error en el contenido del mismo es únicamente responsabilidad de las autoras.

\section{ABREVIATURAS}

\section{AE: L'Année Épigraphique}

CF-Nor: Fontes epigraphici religionum Celticarum antiquarum. Volumen I: Provincia Noricum

CIL: Corpus Inscriptionum Latinarum

CIRG: Corpus de Inscripciones Romanas de Galicia

CLE: Carmina Latina Epigraphica

FE: Ficheiro Epigráfico

FIRA: Fontes luris Romani Antiqui

HAEp: Hispania Antiqua Epigraphica

ILAlg: Inscriptions Latines de L'Algérie

ILJug: Inscriptiones Latinae quae in Iugoslavia...repertae et editae sunt

LMentana: Barbieri (ed.), 1982, Il lapidario Zeri di Mentana N.S.: Notizie degli Scavi di Antichità

\section{BIBLIOGRAFÍA}

Abascal, J.M., 1995. Las inscripciones latinas de Santa Lucía de Trampal (Alcuescar, Cáceres) y el culto de Ataecina en Hispania. AEspA 68, 31-105.

Abásolo, J.A., Elorza, J.C., 1974. Nuevos teónimos de época romana en el País Vasco-Navarro. EAA 6, 247-258.

Albertos Firmat, M.L., 1970. Álava prerromana y romana. Estudio Lingüístico. EAA 4, 107-234.

Andreu, J., 2012. Aspectos sociales del culto a las aguas en Hispania: las dedicaciones a las Nymphae. In: Bost, J.-P. (Dir.), L'Eau: usages, risques et représentations dans le SudOuest de la Gaule et le Nord de la péninsule Ibérique, de la fin de l'âge du Fer à l'Antiquité tardive (Ile s. a.C.- Vle s. p.C.), 333-348. Aquitania, Bordeaux.

Andreu, J., 2017a. La sacralización del agua en la Hispania romana: una perspectiva epigráfica. In: Perex Agorreta, M.J., Miró i Alaix, C. (Eds.), Ubi aquae ibi salus. Aguas mineromedicinales, termas curativas y culto a las aguas en la Península Ibérica (desde la Protohistoria a la Tardoantigüedad), 84-113. UNED, Madrid.

Andreu, J., 2017b. Catálogo epigráfico. In: Perex Agorreta, M.J., Miró i Alaix, C. (Eds.), Ubi aquae ibi salus. Aguas mineromedicinales, termas curativas y culto a las aguas en la Pe-

\footnotetext{
${ }^{21} \mathrm{~A}$ diferencia de lo que se observa en un epígrafe de Edeta, en el que el locus sacer asociado a las Ninfas se identifica con el término templum (CIL II2/14, 121: Templum Nympharum / Q(uintus) Sert(orius) Euporistus / Sertorianus et Sert(oria) / Festa uxor a solo / ita uti exculptum / est in honorem Edetanor(um) / et patronorum suorum / s(ua) p(ecunia) fecerunt), en nuestro caso no podemos establecer su identificación. Sobre el vocablo templum y su posible identificación con ara cabe citar el carmen conservado en el ara dedicada a Diana procedente de la ciudad de León (CIL II, 2660b; CLE 1526A), donde se lee Ae[q]uora conclusit campi / diuisque dicauit / et templum statuit tibi/... En opinión de Rabanal Alonso, García Martínez (2001: 89 n. 102) el término templum estaría aludiendo a la propia ara. Sobre los lugares de culto en las ciuitates romanas vid. Scheid 2010
} 
nínsula Ibérica (desde la Protohistoria a la Tardoantigüedad), 169-370. UNED, Madrid.

Barandiarán, J.M. de, 1925. Eusko Folklore: materiales y cuestionarios. Eusko-lkaskuntza = Sociedad de Estudios Vascos, año $V, n^{\circ} L X, 45-48$

Beltrán-Lloris, M., Paz, J.Á., 2004. Las aguas sagradas del Municipium Turiaso. Caesaraugusta 76

Benseddik, N., 2005. Esculape et Hygie. Les cultes guérisseurs en Afrique. Pallas 68, 271-288.

Castillo, P., 2000. Las propiedades de los dioses: los loca sacra. Iberia 3, 83-109.

Corta, J.M., 1928. Vías romanas de Álava. Monumentos arqueológicos. Euskalerriaren Alde XVIII, 326-361.

Cibu, S., 2003. Chronologie et formulaire dans les inscriptions religieuses de Narbonnaise et des provinces Alpines (Alpes Graies et Poenines, Cottiennes et Maritimes). Revue archéologique de Narbonnaise 36, 335-360.

De Hoz, J., 1986. La religión de los pueblos prerromanos de Lusitania. In: VV.AA. (Eds.), Manifestaciones religiosas en la Lusitania, 31-49. Universidad de Extremadura, Cáceres.

De Hoz, J., 1993. Testimonios lingüísticos relativos al problema céltico en la Península Ibérica. In: Almagro-Gorbea, M., Ruiz Zapatero, G. (Eds.), Los Celtas: Hispania y Europa, 357-403. Editorial Actas, Madrid.

De Ruggiero, E. 1961. Dizionario Epigrafico di Antichità Romane. Ristampa anastática invariata del original de 1900.Vol I y IV. L'Erma di Bretschneider, Roma.

Delgado-Delgado, J.A., 2016. Religión y culto en el ara Pacis Augustae. AEspA 89, 71-94.

Diez de Velasco, F., 1998. Termalismo y religión. La sacralización del agua termal en la Península Ibérica y el norte de África en el mundo antiguo. Monografía $n^{\circ} 1$ de 'llu. Universidad Complutense, Madrid.

Diez de Velasco, F., 2008. Mutation et perduration de l'espace sacrée: l'exemple du culte des eaux thermales dans la Penínsule Ibérique jusqu'à la romanisation. In: Dupré Raventós, $X$., Ribichini, S., Verger, S. (A cura di), Saturnia Tellus. Definizioni dello spazio consacrato in ambiente etrusco, italico, fenicio-punico, iberico e celtico. Atti del convegno internazionale svoltosi a Roma dal 10 al 12 novembre 2004, 457-469. Consiglio Nazionale delle Ricerche, Roma.

Dubourdieu, A., Scheid, J., 2000. Lieux de culte, lieux sacrés: les usages de la langue. In: Vauchez, A. (Dir.), Lieux sacrés, lieux de culte, sanctuaires. Approches terminologiques, méthodologiques, historiques et monographiques, 59-80. École Française de Rome, Roma.

Elorza, J.C., 1967. Ensayo topográfico de epigrafía romana alavesa. EAA 2, 119-186.

Elorza, J.C., 1972. Religiones del País Vasco-Navarro en época romana. Estudios de Deusto 20, 357-366.

Elorza, J.C., 1974. Nuevos teónimos de época romana en el País Vasco-Navarro. EAA 6, 247-258.

Ehmig, U., 2015. Guter Gott! Bonus Deus in lateinischen Fluchtafeln. Graeco-latina Brunensia 20(2), 3-15.

Fernandes, L. da Silva, 2002. As àguas e o factor religioso na provincia romana de Lusitania. In: Ribeiro, J. Cardim (Coord.), Religiões da Lusitania. Loquuntur Saxa, 131-140. Museo nacional de Arqueología, Lisboa.
Fernández Corral, M., 2016. Conmemoración funeraria y religiosa de época romana en la epigrafía del norte de Hispania: el área autrigona/Funerary and religious commemoration in the Roman era epigraphy of the Northern Hispania: te area of the autrigones. Tesis Doctoral, Vitoria-Gasteiz.

Fugier, H., 1963. Recherches sur l'expression du sacré dans la langue latine. Les Belles Letres, Paris.

Guerra, A., 2015. Uma consagração aos deuses bons proveniente de Lisboa (Olisipo) (Conuentus Scallabitanus). FE 128.

Hainzmann, M., 2006. Bedaios und das sacrum Alo(v)narum, In: Angeli Bertinelli, M.G., Donati, A. (a cura di), Misurare il tempo, misurare el spazio. Atti del Colloquio AIEGL-Borghesi 2005, 455-477. Fratelli lega editori, Faenza.

Hainzmann, M., 2017. Aesculapius et Hygia als Dii maiores? Studia Europaea Gnesnensia 16, 259-279.

Instituto Alavés de Arqueología, 1981. Excavaciones en el siglo XVIII en el yacimiento romano de Cabriana (Comunión-Álava). EAA 10, 307-310.

Lambert, P-Y., 2013. Le statut du théonyme gaulois. In: Hofeneder A., De Bernardo Stempel, P. (Hgg.), Théonymie celtique, cultes, interpretatio / Keltische Theonymie, Kulte, interpretatio. X. Workshop F.E.R.C.AN., Paris, 24-26 Mai 2010. Mitteilungen der Prähistorischen Kommission 79, 113-124.

Laubry, N., 2012. Des rites pour le faire, des mots pour le dire: désignations, conceptions et perceptions de l'espace funéraire à Rome (ler siècle av. J.-C. - Ille siècle apr. J.-C.). In: De Souza, M., Peters-Custot, A., Romanacce, F.-X., Le sacré dans tous ses états. Catégories du vocabulaire religieux et sociétés, de l'Antiquité à nos jours, 10, Publications de I'université de Saint-Étienne, 169-180. Bibliotheque du CERHI, 978-2-86272-609-0.<halshs-01303334> (consultado el 12/06/2019).

Leite de Vasconcellos, J., 1988. Religiões da Lusitânia na parte que principalmente se refere a Portugal, vol. 3. Impresa Nacional-Casa da Moeda. Facsímil de la edición de 1913, Lisboa.

Lhote-Birot, M.-Ch., 2004. Les Nymphes en Gaule Narbonnaise et dans les Trois Gaules. Latomus 63(1), 58-69.

Lostal, J., 1992. Los miliarios de la provincia Tarraconense. Institución Fernando el Católico, Zaragoza.

Navarre, O., 1907. Nymphae. Dictionnaire des antiquités grecques et romaines, IV, parte $1^{\mathrm{a}}(\mathrm{N}-\mathrm{Q}), 124-128$

Olivares-Pedreño, J.C., 2002. Los dioses de la Hispania céltica. Universitat de Alacant y Real Academia de la Historia, Alacant.

Olivares Pedreño, J.C., 2013. La omisión del dedicante en las inscripciones votivas de Hispania como indicio de su ubicación en ámbitos privados. Studia Historica, $\mathrm{H}^{\mathrm{a}}$ Antigua 31, 59-87.

Ortiz de Urbina-Álava, E., 1985. Los autrigones según las fuentes escritas (época prerromana y altoimperial). Memoria de Licenciatura, Vitoria-Gasteiz.

Rabanal Alonso, M.A., García Martínez, S., 2001. Epigrafía romana de la provincia de León: revisión y actualización. Universidad de León, León.

Rapsaet-Charlier, M.-Th., 1993. Dis deabusque sacrum. Formulaire votif et datation dans les Trois Gaules et les deux Germanies. De Boccard, Paris.

Rapsaet-Charlier, M.-Th., 2001. Le formulaire des dédicaces religeuses de Germanie supérieure. In: Spickermann, W. (Hg.), 
Religion in dem germanichen Provinzen Roms, 135-171. Mohr Siebeck, Tübingen.

Real Academia de la Historia, 1802. Diccionario Geográfico-Histórico. 2 vols. Imprenta de la Viuda de Joaquín Ibarra, Madrid.

Ruiz Sáez, S., 2008. Testimonios epigráficos y contexto arqueológico del culto a las Ninfas en la Península Ibérica, a excepción del Noroeste. Sautuola 14, 217-240.

Saglio, E., 1877. Bona Dea. Dictionnaire des antiquités grecques et romaines, I, parte $1^{\text {a }}(A-B), 725-726$.

Scheid, J., 1992. Épigraphie et sanctuaires guérisseurs en Gaule. MEFRA 104, 25-40.

Scheid, J., 2005. Les Götternamen de Hermann Usener: une grande Théogonie. In: Belayche, N., Brulé, P, Freyburger, G., Lheman, Y., Pernot, L., Prost, F. (Textes réunis et édités par), Nommer les Dieux. Théonymes, épithètes, épiclèses dans l'Antiquité, 93-103. Brepols-Presses Universitaires de Rennes, Turnhout.

Scheid, J., 2008. Religion, institutions et société de la Rome antique. Cours: Le culte des eaux et des sources dans le monde romain. Annuaire du Collège de France 108, 622-637.

Scheid, J., 2010. Siue in ciuitate... siue in agro. Réflexions sur le statut des lieux de culte situés sur le territoire des cités. In: Genière, J. de la, Vauchez, A., Leclant, J. (Éds.), Les santuaires et leur rayonnement dans le monde Méditerranéen de l'Antiquité a l'époque moderne. Actes, 141-159. De Boccard, Paris.
Scheid, J., 2012. Des divinités meurent. Réflexions sur les Nymphes. In: d'Intino, S., Guenzi, C. (Sous la direction de), Aux abords de la clairière. Études indiennes et comparées en I'honneur de Charles Malamoud, 163-171. Brepols, Turnhout.

Sebaï, M., 2010. Sacerdos intrauit sub iugum. Étude sur le rituel dans le culte de Saturne en Afrique romaine. Cahiers Glotz 21, 269-284.

Solana, J.M., 1978. Autrigonia romana: Zona de contacto Castilla-Vasconia. Universidad de Valladolid, Valladolid.

Torres, M., 1981. Los mosaicos descubiertos en el siglo XVIII en la villa de Cabriana (Álava). EAA 10, 311-340.

Toutain, J., 1967. Les cultes Païens dans l'empire romain. Tome I. Les provinces latines, 381-384. L'Erma di Bretschneider. Ristampa anastática invariata dell'edizione Paris 19051907.Vol I, A-B, Roma.

Untermann, J., 1985. Los teónimos de la región lusitano-gallega como fuente de las lenguas indígenas. In: De Hoz, J. (Ed.), Actas del III Coloquio sobre lenguas y culturas paleohispánicas (Lisboa, 5-8 noviembre 1980), 343-363. Ediciones Universidad de Salamanca, Salamanca.

Wedenig, R., 2016. ...habeamus Bonum Eventum semper propitium- eine singuläre Wunschlitanei mit Götternamen aus Vindobona/Wien. Carnuntum Jahrbuch, 91-99.

Wissowa, G., 1912. Religion und Kultus der Römer. C.H. Beck'sche Verlagbuchhandlung, München. 